\title{
A Review of Parametric Design of Tall Buildings
}

\author{
Görkem Arslan Kılınç ${ }^{1}$ and Ayşin Sev ${ }^{2}$ \\ ${ }^{1}$ Mimar Sinan Fine Arts University, Faculty of Architecture, Department of Construction Technology \\ Meclis-I Mebusan Street, No:24, 34427, Beyoğlu, Istanbul, Turkey \\ ${ }^{2}$ Mimar Sinan Fine Arts University, Faculty of Architecture, Department of Construction Technology \\ Meclis-I Mebusan Street, No:24, 34427, Beyoğlu, Istanbul, Turkey
}

\begin{abstract}
Historically, the development of tall buildings has been dependent on technological advancements. As the continuous advancement in construction technologies impacted tall building design, the architectural profession changed with the rapid technological progresses. One of the recent remarkable advancements in construction technologies is the utilization of digital tools in tall building design and construction. From this point of view, this study aims to shed light on the current studies of the parametric design of tall buildings after briefly discussing the birth and development of parametric design.
\end{abstract}

Keywords: parametric design, tall buildings, high-rise buildings, digital tools, construction technology

\section{Development of Tall Buildings with the Progression of Technology}

167 years ago, in 1851, a pioneer building, "Crystal Palace" was designed in London by Joseph Paxton. This building embodied the technological spirit of the Industrial Age and revealed the power of glass and steel as construction materials. 36 years later, in 1887, with the construction of Eiffel Tower "soaring heights", which new buildings could reach, became a focus for architects and engineers [3].

In the same era, in 1885, Home Insurance Building, which is accepted as the first tall building of the world by many authorities, was built in Chicago [1]. According to technological advancements of the era, the building had cast and wrought iron columns, wrought iron beams and girders, and thick masonry walls, which provided lateral resistance to wind loads.

The era of rapid development of tall building construction was 1880s and 1890s. This era illustrated the introduction and development of steel-framing technology [9]. By the end of the 19th century, the "skyscraper" was a popular building type. Fireproofed, steel-framed constructions dominated the skylines of Chicago and New York.

With the Great Depression in 1930s and the World War II (1939-45), there was a decline in tall building construction until the 1950s. Following the World War II with the advance of computer technology and analytical technics, new structural systems were developed, facilitating the construction industry. It was now possible to analyse and investigate different structural systems and components with the aid of the computer, which had never been possible before. Conventional rigid frame systems were the prevalent structural systems for tall buildings. In this era, the major driving force for tall building developments was simplicity and economy.

By the Modernism, initiating after the World War II, the development of glazed curtain-wall systems, advancements in air-conditioning systems and impression of modern architecture, a number of architects designed and built many buildings in large rectangular forms, with deep office floor plans, such as Lake Shore Drive Apartments and Lever House [3, 15]. 
1970s were the times of major structural innovations. A young engineer Fazlur Khan, working by Skidmore Owings and Merrill in New York, utilized new methods of computer calculation to three-dimensionally analyse the effects of wind on structures. As a result of his studies, he put forward a new structural idea for tall buildings: tubular systems. Tubular systems were based on the idea that a building can be designed to resist lateral loads by an exterior shear wall, in the form of a tube, which was comprised of closely spaced columns tied together with deep spandrel beams through moment-resisting connections. With this new structural concept, numerous giant structures such as the World Trade Centre and Willis Tower was built with tubular system [1].

Due to the improvements in computational design at 1990's, similar to Crystal Palace and Eiffel Tower designs after Industrial Revolution, another pioneer building "Guggenheim Museum" was designed by Frank Gehry as a sign of "Digital Age" (Fig.1). This building is probably the best known example that captures the zeitgeist of the digital information revolution [2].

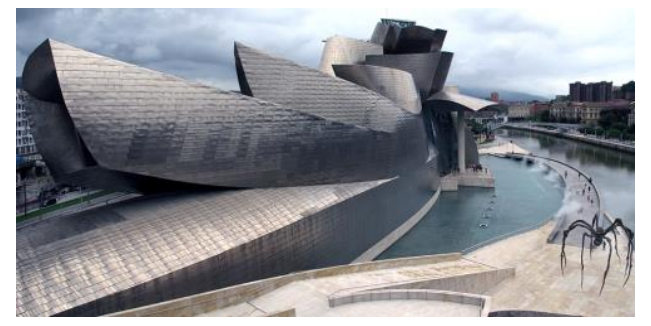

Fig. 1: Guggenheim Museum, Bilbao-Spain, 1993-1997 [20].

On the other hand, in the same period again with the help of the computational calculation and design, another innovative structural system which was called "mega frames" was developed. Mega frames (MFs) can be configured with mega columns on building perimeter, a rigid core consisting of shear walls and outriggers linking the core to the mega columns. The MFs are considered to be reliable and efficient for tall buildings in ultra-heights, since they offer structural efficiency by providing high rigidity against lateral loads, with a minimum amount of structural materials. Today most of the buildings taller than 70 stories are supported by mega-frames. The Petronas Twin Towers (Kuala Lumpur, 1998), Jin Mao Tower (Shanghai, 1999), all utilize the concept of mega frames.

In accordance with the past, similar to the Industrial Revolution effects on tall building's design and construction, today information revolution and digital age is effecting tall building's design and manufacturing processes. Iconic forms which were impossible to design and construct earlier are designed and built today.

On one hand digitalized computation based generative modelling tools such as Generative Components, Rhinoceros, Grasshopper etc. and on the other hand computational analytic tools as ETABS and so on enhancing our imagination concerning tall buildings.

Swiss Re Building, designed by Sir Norman Foster, is a pioneer example of the utilization of computer-aided design technologies in architectural practice (Fig.2). In the design process of this building, constructing and detailing of quadrilateral façade panels with different openings and concavities were the biggest challenges.

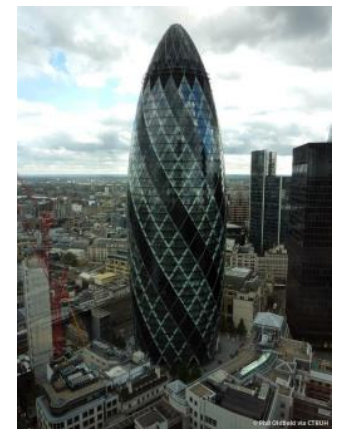

Fig. 2: Swiss Re Building, London-UK, 2004 [21]. 
A facade firm working in London and many other cities in Europe created its own three-dimensional model for the building. The model was inspected by architects and engineers and manufactured with CNC machines with a special software. This approach allows both the visualize of the structural system before construction and prevent human errors."

\section{A Brief History of Computer-Aided Design Guide for Author}

Preliminary entities about computer-aided design can be seen at 1960's as 2D drawings and splines. In time, these early entities expanded to 3D frames and planes [7].

In 1963 a Ph.D student at MIT, Ivan Sutherland, introduced a new drawing system, which was named "sketchpad system" [17]. Today, this system is being considered as the earliest work to modern computer-aided drafting (CAD) [12]. This invention was followed by the activities as computer graphics in architecture. At the end of the 1960s conferences about computer-aided design were started to be carried out by academicians, architects and engineers. The 1970s witnessed extensive coverage of computer graphics, and this new research area became more acknowledged.

During this period, many books were published exploring the use of computers in different areas. For the first time in the 1980s, the use of personal computers was opened, and Evans and Sutherland introduced the first commercial CAD package usage [7].

The broad adaptation of computer technology to the architectural field was around 1990's. One of the important contribution of computer technology to the design field is the ability to generate new forms with these tools. This generative potential of CAD tools are opening new dimensions in architectural design [19].

The multifaceted possibilities provided by computer-aided design technologies have led to the formation of different sub-headings in the field of architectural design. Topological architecture, isomorphic architecture, animated architecture, metamorphic architecture, evolutionary architecture and parametric architecture are the main ones of these sub-headings [2].

In this study, parametric design which have qualities to meet the needs of tall building design and the relation of parametric design and tall buildings will be discussed in detail.

\section{Parametric Design in Architecture}

Parametric design refers to the definition of a form by means of parameters and relations. In the literature, relational modelling, variational design or rule-based design (constraint-based design) is also known by the name [7].

In the past 15 years, use of digital design within the discipline of architecture led to a different architectural understanding. Computer aided design tools, which were used as architectural presentation and representation tools in the past, are using effectively both in form production processes and performance analyses in the design processes today.

There are two basic approaches of the parametric design. According to first approach all designs are actually parametric, since many parameters such as legal limitations, orientation, solar radiation, wind etc. should be taken into account when designing a building. According to the second approach, parametric designs are designed with a specific designer tool, such as Grasshopper, Maya MEL, Rhino Scripting, Processing, which directs and associates design components simultaneously [11].

In parametric design, the variables, which affect the design are determined and regulated as parameters. A design strategy is established by specifying numerical and geometric relations between these parameters. In other words, parametric models are formed by the regulation of rules and constraints. Changing a rule or constraint or reshaping a part of the model results in changes to the entire model $[19,8]$.

In models with associative geometry, instead of metric values of the shapes, relations of them are important. Thus, parameters can take any metric values [5]. In terms of metric values of the parameters all geometric data 
associated with them redefines. For example, changing story height in a building with a fixed height, lead to change in the number of floors. This potential of the parametric models provides more accurate and reliable design decisions (change of floor plans, optimum value of total floor area, etc.) than conventional methods [5].

In other words, there is no single answer to the resolution of design problems. The answer consists of a set of different variations. The designer aims to find the most appropriate solution in this set of variations with new definitions and new design ideas. Parametric design makes it possible for the designer to make different variations in a short time.

\section{Parametric Design of Tall Buildings}

Numerous design components related to each other play an active role in the design of tall buildings. The design criteria of these components can be inversely proportional to each other. During the design of a tall building, it is a difficult process to achieve a design with optimum values in terms of architectural and structural components.

Additionally, tall buildings are designed within the framework of the rules specified in the early design process, changes depending on the results of both performance analyses and wishes of the employer releases new problems. In such a case, using CAD tools only for representational purposes requires a lengthy and difficult process.

For instance, depending of the height of the building and the type of the structural material, cost of the building structure can reach up to $30 \%$ of the total cost. In conventional design process, structural design decisions are taken after determination of the building form. In the ongoing process concerning efficiency and cost of the structure, architectural form of the building is re-evaluated. At the end of such a design process, although the construction of the structure is realized, it cannot be said that the conceptual, formal, technical and financial structures have optimum values [14].

Similar examples can be found in other areas of performance of the build. Reducing "exterior facade area/floor space" ratio optimizes material usage and total cost of the construction due to reducing horizontal loads. On the other hand, reducing this ratio usually requires non-orthogonal building forms. In such a case, optimization of all design components with conventional design methods poses difficulties [4].

Today, developing software's and techniques play a pivotal role in addressing these design challenges. Parametric modelling systems are effective in creating a cluster of complex geometric and multivariable design alternatives. Additionally, besides form generation techniques, analytic performance analyse software's creates another research area [14].

Figure 3 shows the some researches that are being investigated in this study and which reveal a new software for tall building parametric design. written as shown below:

\begin{tabular}{|l|l|l|}
\hline Year & Author & Title \\
\hline 2015 & $\begin{array}{l}\text { William Suyoto, Aswin Indraprastha } \\
\text { Heru W. Purbo }\end{array}$ & $\begin{array}{l}\text { Parametric Approach as a Tool for Decision-making in Planning and Design Process. } \\
\text { Case study: Office Tower in Kebayoran Lama. }\end{array}$ \\
\hline 2014 & $\begin{array}{l}\text { Lauren L. Beghini, Alessandro Beghini } \\
\text { Neil Kat, William F. Baker } \\
\text { Glaucio H. Paulino }\end{array}$ & Connecting arehitecture and engineering through structural topology optimization. \\
\hline 2012 & $\begin{array}{l}\text { Goman Wai-Ming Ho } \\
\text { Peng Liu, Michael Liu }\end{array}$ & Parametric Design Analysis and Design Engine for Tall Building Structures \\
\hline 2011 & Ayman M. Almusharaf & Incorporating the Structure of Tall Buildings within an Architectural Form Generation Process \\
\hline 2011 & Hyeong-Il Kim, Sungwoo Shin & A Study on Innovation in Technology and Design Variation for Super Tall Buildings \\
\hline 2010 & Mahjoub Elnimeiri, Ayman Almusharaf & S Design Optimization Workflow for Tall Buildings Using Parametric Algoritm \\
\hline $\mathbf{2 0 1 0}$ & Hans Hubers & Collaborative Parametric BIM \\
\hline $\mathbf{2 0 1 0}$ & Ayman Almusharaf, Mahjoub Elnimeiri & A Performance-Based Design Approach for Early Tall Building Form Development \\
\hline $\mathbf{2 0 0 6}$ & Shouheng Chen & Embedding Methods for Massing and Detail Design in Computer Generated Design of Skyscrapers \\
\hline $\mathbf{2 0 0 5}$ & Sang Min Park & Tall Building Form Generation by Parametric Design Process \\
\hline $\mathbf{2 0 0 5}$ & $\begin{array}{l}\text { Kristina Sheaa, Robert Aishb } \\
\text { Marina Gourtovaiaa }\end{array}$ & Towards Integrated Performance-Driven Generative Design Tools \\
\hline
\end{tabular}

Fig. 3: Tall building-parametric design studies. 
For instance, Sang Min Park (2005) worked on the tall building form generation by parametric design process within the scope of her/his Ph.D. In this study, variant parameters (top and bottom geometry and form geometry -morph, setback, twist, curvilinear) are examined by constant parameters (function of the building, floor height, design of core, the distance between core and exterior wall) with the aid of a software which was created using Auto Lisp programming language. With the help of a solution set, characteristic features are presented for 4 form (morph, setback, twist, curvilinear) clusters.

In another study, in order to be able to parametrically perform form and detail design in early design stages of tall buildings, Chen (2006) developed an additional software for Rhino software. Digital Skyscraper software has been tested on Petronas Towers, Hearts Tower, Hong Kong International Finance Center and Tower of Jira, and has achieved successful results.

Almusharaf (2011) has also carried out a research on the relation between the parametric form generation and structural design of tall buildings within the scope of his doctoral study. Main aim of this study, with configuring a relation between generative and analytic tools, is designing form and structure of a tall building together in the early design process. From this point of view, the software generative components for form generation and ETABS for structural analyse were selected. An interface was created using the Visual Basic software language. This interface is intended to establish a repetitive design process between the generative and the analytical software's.

In our age, tall building designers aim to realize designs with formal, technological and ecological innovations. Using parametric design tools both generative and analytic manner stands out as an effective way. One of the most interesting example of using both generative and analytic tools in tall building design can be seen in the design process of Shanghai Tower (2015) in China (Fig.4).

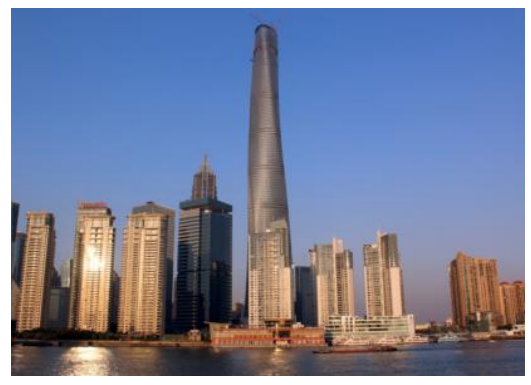

Fig. 4: Shanghai Tower, Shanghai-China, 2015 [22].

The Shanghai Tower is a $632 \mathrm{~m}(2,073 \mathrm{ft})$ and 128 story mega tall skyscraper in Shanghai. The building is divided into nine zones with five main functions: office; boutique office; luxury boutique hotel; themed retail, entertainment and cultural venues at the podium; and the observation experience at the tower's pinnacle. Due to buildings unique form, every floor of the building is different. Although all floors have the same shape, each floor is rotated $1 \%$ from the floor below and floors scale down as the building rises. The design team used parametric software to define the building's complex geometry and to create an associative model integrating the building and façade.

For optimize the curvature of the corners to meet aesthetic, functional, and sustainable criteria (to optimize the appearance of the corners and the use of the atria that were created between outer and inner facades, to balance the building's gross floor area, and to minimize the effect of wind loading) design team entered basic data into parametric software (rhino with grasshopper) and changed the key angle to produce different corner configurations (Fig.5). Similarly, rotation degree, base to top scaling and curtain wall support structure system of the tower are decided with the help of rhino software concerning sustainability issues. 


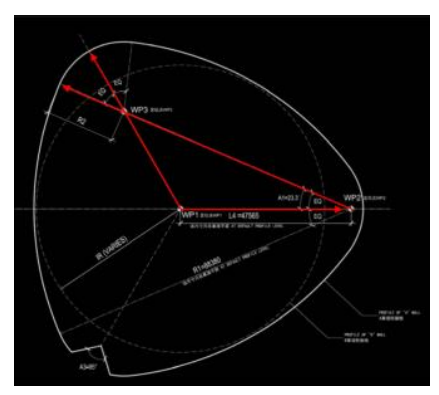

Fig. 5: Producing optimum curvature of the corners of Shanghai Tower [16].

An example of using both generative and analytic design tools can be seen in the design process of the curtain wall support structure. Unlike the pointed tops of most supertall buildings, the top of Shanghai Tower is an opening that allows for the sustainable features of wind turbines and rainwater collection. The split-parabolic curve of the outline of the tower was technically challenging to resolve. Data from the curtain wall geometry was exported from Grasshopper to Excel. Resulting data was then reintroduced to Grasshopper to generate a steel structure parametric model using the structural engineer's parameters. Steel geometric data-including the end coordinates of straight steel members and the radii and sweep angles of curved steel members - was then exported back to Excel. The resulting data was imported into Autodesk Revit to generate the steel structure model. Since Revit could read the Excel file directly without any exchange file, the design team wrote a script with Microsoft Visual C\# that ran between Grasshopper and Revit. Finally, the team utilized the Revit model to generate the construction drawings.

\section{Conclusions}

In this study, several researches on the parametric design of tall buildings have been examined.

From the 19th century to the present, tall buildings have changed and developed in parallel with technological developments. As a result of advancements in computational design, today digital tools are using not only for representational but also for generative purposes. Iconic forms which were impossible to design and construct before, are designed and built today with the help of computational technologies. This improvement pushes the boundaries of how architecture is perceived by the society and architects.

As mentioned before, numerous related design components play an active role in the design of tall buildings. Rather than conventional methods, designing with the parametric softwares, helps to make optimum design decisions. Parametric models allowing modifications in the later stages of design, making it possible to handle the design process in a repetitive manner. In addition, the ability to switch between the generative and analytical parametric softwares in the design process ensures ease and reliability in design of tall buildings. And emerges as a contemporary research area.

\section{References}

[1] A. Sev, Innovations in Tall Building Design and Technology: From Balloon Frame to the Megastructures, 1 st ed. Germany: Scholars' Press, 2015, pp.25-45.

[2] B. Kolarevic, Architecture in the Digital Age: Design and Manufacturing, ed. B. Kolarevic, New York: Spon Press, 2003, pp.1-17.

[3] M. Wigginton, Glass in Architecture, Hong Kong: Phaidon Press, 1996, pp.58.

[4] H. I. Kim and S. Shin, "A study on innovation in technology and design variation for super tall buildings," Journal of Asian Architecture and Building Engineering, vol. 10, pp. 61-68, May 2011.

https://doi.org/10.3130/jaabe.10.61

[5] D. Scott, D. Farnsworth, M. Jackson and M. Clark, "The effects of complex geometry on tall towers," Structural Design Tall Spec. Build,. vol. 16, pp. 441-455, 2007. 
https://doi.org/10.1002/tal.428

[6] L. L. Beghini, A. Beghini, N. Katz, W. F. Baker and G. H. Paulino, "Connecting architecture and engineering through structural topology optimization,” Engineering Structures, vol. 59, pp. 716-726, December 2014. https://doi.org/10.1016/j.engstruct.2013.10.032

[7] J. Monederro, "Parametric design: a review and some experiences," Automation in Construction, vol. 9, pp. 369-377, 2000.

https://doi.org/10.1016/S0926-5805(99)00020-5

[8] K. Shea, R. Aish and M. Gourtovaia, "Towards integrated performance-driven generative design tools," Automation in Construction, vol. 14, pp. 253-264, 2005.

https://doi.org/10.1016/j.autcon.2004.07.002

[9] D. Friedman, "Hidden intricacies: the development of modern building skeletons," APT Bulletin, vol. 43, 13-21, 2012.

[10] G. W. Ho, P. Liu and M. Liu, "Parametric analysis and design engine for tall building structures," International Journal of High-rise Buildings, vol. 1, pp. 35-59, 2012.

[11] W. Suyoto, A. Indraprastha and H. W. Purbo, "Parametric approach as a tool for decision-making in planning and design process. Case study: Office tower in Kebayoran Lama" Procedia-Social and Behavioral Sciences vol. 184, pp. 328-337, 2015.

https://doi.org/10.1016/j.sbspro.2015.05.098

[12] T. Vardouli, "Computer of a thousand faces: anthropomorphizations of the computer in design (1965-1975)," Dosya 29, pp. 24-32, November 2012.

[13] M. Elnimeiri, M. Nicknam, "A Design Optimization Workflow for Tall Buildings Using Parametric Algorithm," in CTBUH Seoul Conference Proceedings, 2011, pp. 561-569.

[14] M. Elnimeiri and A. Almusharaf, "Structure and architectural form of tall buildings," in International Conference on Sustainable Building Asia Proceedings, 2010, pp.54-60.

[15] F. M. Butera, "Glass architecture: is it sustainable?" in Proc. of the International Conference Passive and Low Energy Cooling for the Built Environment, 2005, pp.161-168.

[16] J. Xia and M. Peng, "The Parametric Design of Shanghai Tower's Form and Façade," in Proc. of CTBUH 9th World Congress, 2012, pp. 112-119.

[17] S. M. Park, "Tall building form generation by parametric design process," Ph.D. thesis, Illinois Institute of Technology, Illinois, USA, 2005.

[18] S. Chen, "Embedding methods for massing and detail design in computer generated design of skyscrapers," M.S. thesis, Massachusetts Institute of Technology, Massachuset, UK, 2006.

[19] A. M. Almusharaf, "Incorporating the structure of tall buildings within and architectural form generation process," Ph.D. thesis, Illinois Institute of Technology, Illinois, USA, 2011.

[20] M. A. Postal, 2018, [available at 12 June 2018] https://tr.khanacademy.org/humanities/ap-art-history/globalcontemporary/a/gehry-bilbao.

[21] Council on Tall Buildings and Urban Habitat, 2018 [available at 12 June 2018] http://www.skyscraper center.com/building/30-st-mary-axe/.

[22] Council on Tall Buildings and Urban Habitat, 2018 [available at 12 June 2018] http://www.skyscraper center.com/building/shanghai-tower/56. 